\title{
Noble Gas, Tritium, And CFC Tracers In A Perennial Firn Aquifer, Southeast Greenland
}

\author{
D. K. SOLOMON ${ }^{1} *$, O. L. MILLER ${ }^{1}$ \\ ${ }^{1}$ Geology and Geophysics, University of Utah, SLC, UT \\ 84112, USA (*correspondence: kip.solomon@utah.edu, \\ omiller@usgs.gov)
}

\section{Background}

Firn aquifers have been recently discovered across regions of the Greenland ice sheet with high snow accumulation and melt rates. Firn in Greenland has the potential to store considerable volumes of meltwater $(300$ to $1300 \mathrm{Gt}$ ), and could contribute up to $0.4 \mathrm{~mm}$ of sea level rise if they drained completely [1]. For the first time, we have measured dissolved noble gases, tritium and CFCs at discrete depths (vertical profiles) over the $20 \mathrm{~m}$ thickness of the aquifer for the purpose of age dating. ${ }^{3} \mathrm{H} /{ }^{3} \mathrm{He}$ dating of liquid water is complicated because ${ }^{3} \mathrm{H}$ can exist in both the liquid and solid phases such that a mass balance must consider the liquid water, solid ice, and encapsulated bubbles as a system. Also, $\mathrm{He}$ (unlike heavier noble gases) is soluble in ice and readily partitions into bubbles. By assuming that all phases (liquid water, ice and bubbles) are in local equilibrium, we have formulated a mass balances such that apparent ${ }^{3} \mathrm{H} /{ }^{3} \mathrm{He}$ ages of the liquid water can be estimated.

\section{Results}

Vertical profiles of apparent ${ }^{3} \mathrm{H} /{ }^{3} \mathrm{He}$ age generally increase with depth, and values are mostly consistent with hydraulic estimates of recharge rates [2]. Furthermore, the ${ }^{3} \mathrm{H} /{ }^{3} \mathrm{He}$ mean residence times are generally consistent with a salt balance model in which salt deposition is leached from the firn and concentrated by ion exclusion at the base of the aquifer. Apparent $\mathrm{CFC}$ ages are not consistent with ${ }^{3} \mathrm{H}$ concentrations and do not match the age of the ice based on accumulation rates. We hypothesize that rapid infiltration through 10 to $20 \mathrm{~m}$ of unsaturated firn precludes CFCs from equilibrating with the firn atmosphere. Although ${ }^{3} \mathrm{H} /{ }^{3} \mathrm{He}$ dating is possible, uncertainties in ages are large due to uncertainties in partition coefficients and the volume fraction of bubbles in the system.

[1] Koenig et al. (2014), Geophysical Research Letters, 41(1),

81-85. https://doi.org/10.1002/2013GL058083. [2] Miller et al. (2018), Geophysical Research Letters, 45(1), 207-215.

https://doi.org/10.1002/2017GL075707. 